Document downloaded from:

http://hdl.handle.net/10251/64598

This paper must be cited as:

Meseguer Anastasio, JE.; Tavares De Araujo Cesariny Calafate, CM.; Cano Escribá, JC.; Manzoni, P. (2015). Assessing the impact of driving behavior on instantaneous fuel consumption. 12th IEEE Consumer Communications and Networking Conference (CCNC 2015). IEEE. doi:10.1109/CCNC.2015.7158016.

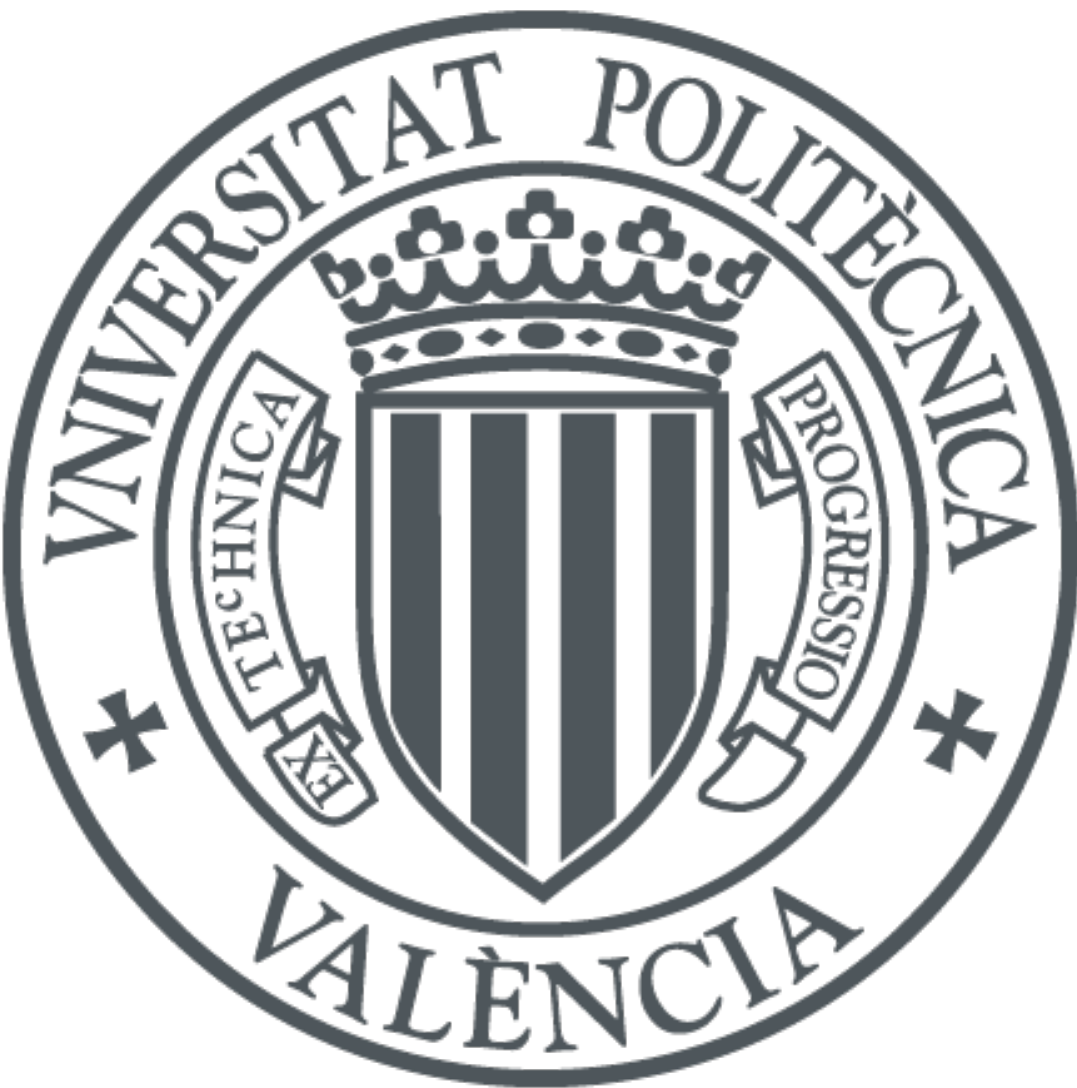

The final publication is available at

http://dx.doi.org/10.1109/CCNC.2015.7158016

Copyright IEEE

Additional Information

(C) 2015 IEEE. Personal use of this material is permitted. Permission from IEEE must be obtained for all other uses, in any current or future media, including reprinting/republishing this material for advertising or promotional purposes, creating new collective works, for resale or redistribution to servers or lists, or reuse of any copyrighted component of this work in other works. 


\title{
Assessing the Impact of Driving Behavior on Instantaneous Fuel Consumption
}

\author{
Javier E. Meseguer, Carlos T. Calafate, Juan Carlos Cano, Pietro Manzoni \\ Department of Computer Engineering Universitat Politècnica de València Camino de Vera S/N, 46022, Spain \\ jmesegue@upvnet.upv.es, \{calafate, jucano,pmanzoni\}@disca.upv.es
}

\begin{abstract}
Despite the recent technological improvements in vehicles and engines, and the introduction of better fuels, road transportation is still responsible for air pollution in urban areas due to the increasing number of circulating vehicles, and their relative travelled distances. We develop a methodology to calculate, in real-time, the consumption and environmental impact of spark ignition and diesel vehicles from a set of variables such as Engine Fuel Rate, Speed, Mass Air Flow, Absolute Load, and Manifold Absolute Pressure, all of them obtained from the vehicle's Electronic Control Unit (ECU). Our platform is able to assist drivers in correcting their bad driving habits, while offering helpful recommendations to improve fuel economy. In this paper we will demonstrate through data mining, to what extent does the driving style really affect (negatively or positively) the fuel consumption, as well as the increase or reduction of greenhouse gas emissions generated by vehicles.
\end{abstract}

Index Terms-Driving styles; Android smartphone; OBD-II; neural networks; eco-driving, consumption, instantaneous fuel consumption, greenhouse gas emissions, $\mathrm{CO2}$.

\section{INTRODUCTION}

The increasing cost of fuel and the environmental pollution caused by greenhouse gas emissions has encouraged the research of more energy efficient vehicles. At the same time, mobile platforms have evolved according to user requirements, and have been applied in different fields of industry such as the automotive, where smartphones are starting to be integrated in vehicles; this clearly opens a new and exciting area of research.

The On Board Diagnostics (OBD-II) [1] standard has recently become an enabling technology for in-vehicle applications due to the availability of Bluetooth OBD-II connectors [2], which enables transparent connectivity between mobile devices and the vehicle's Electronic Control Unit (ECU).

Among the different strategies to reduce fuel consumption and greenhouse gas emissions, the DrivingStyles' platform [3] aims to sensitize drivers about their driving style, making them aware that the driving style is directly related to fuel consumption and gas emissions.

DrivingStyles implements a solution based on neural networks which is capable of characterizing the type of road on which the vehicle is circulating, as well as the driving style of each user [3]. In order to achieve this, the data is obtained from the ECU via the OBD-II Bluetooth interface, including the speed, acceleration, and revolutions per minute of the engine.

In this paper we improve the DrivingStyles' platform by calculating the instantaneous fuel consumption; in this platform, the following variables are obtained in real time: mass flow sensor (MAF), manifold absolute pressure (MAP), and intake air temperature (AIT). Currently, this information is being collected and used in applications aimed at improving road safety and to promote eco-driving [4], thus reducing fuel consumption and greenhouse gas emissions. Specifically we find that, by shifting towards a more efficent driving style, users can save up to $20 \%$ of fuel while improving driving safety [17], [18].

This paper is organized as follows: in the next section we present some related works. Section III introduces the DrivingStyles architecture. Both client and server side applications are described in more detail in section III. The calculations consumption and $\mathrm{CO}_{2}$ emissions are presented in sections IV and V, respectively. Section VI presents the performance results we obtained. Finally, section VII concludes our work.

\section{RELATED WORK}

One of the main problems of eco-driving systems [4] is identifying the factors that affect energy consumption. Ericsson [5] suggests that, in order to save fuel, sudden changes in acceleration and high speed driving should be avoided. Johansson et al. [6] suggest maintaining low levels of deceleration, minimizing the use of the first and second gears, and using, when ever possible, the 5th and 6th gears, while avoiding continuous gear shifts. There are several proposals that analyze which variables affect fuel consumption. Kuhler [10] introduced a set of ten variables that are used in laboratories for fuel consumption and vehicle emissions. Other authors such as André [11] and Fomunung [12] improve these results by increasing and replacing some of the parameters.

In previous works such as D.Y.C. Leung [7] and COPERT III [8], different tools were developed to collect in real time the engine and vehicle parameters from the OBD connector. Moreover, in conjunction with an exhaust analyzer Horiba OBS [9], a set of consumption and emission models were developed for vehicles equipped with spark ignition engines. Several commercial OBD-II scanner tools are available, that can read and record these sensor values. Apart from such scanners, remote diagnostic systems such as GMs OnStar, BMWs ConnectedDrive, and Lexus Link [13], [14] are capable of monitoring engine parameters from a remote location.

Our solution differs from all the previous ones by providing an analysis of the driving style for each user in the scope of eco-driving behavior based on neural network techniques. By calculating the consumption and greenhouse gas emissions generated by both types of engines (spark ignition and diesel 
http://www.drivingstyles.info

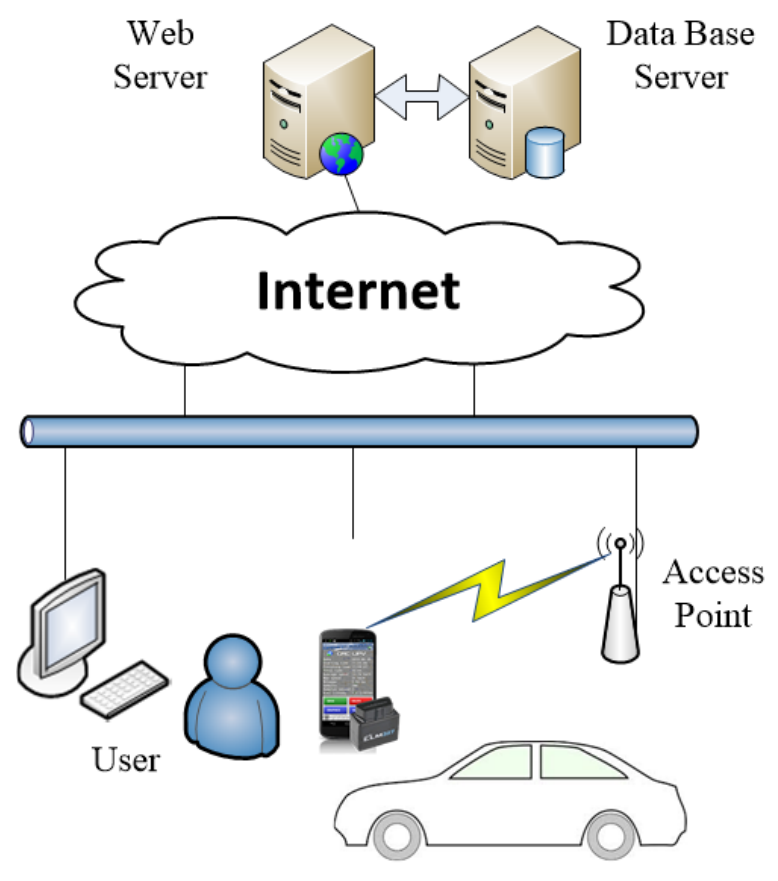

(a) Overview of the architecture

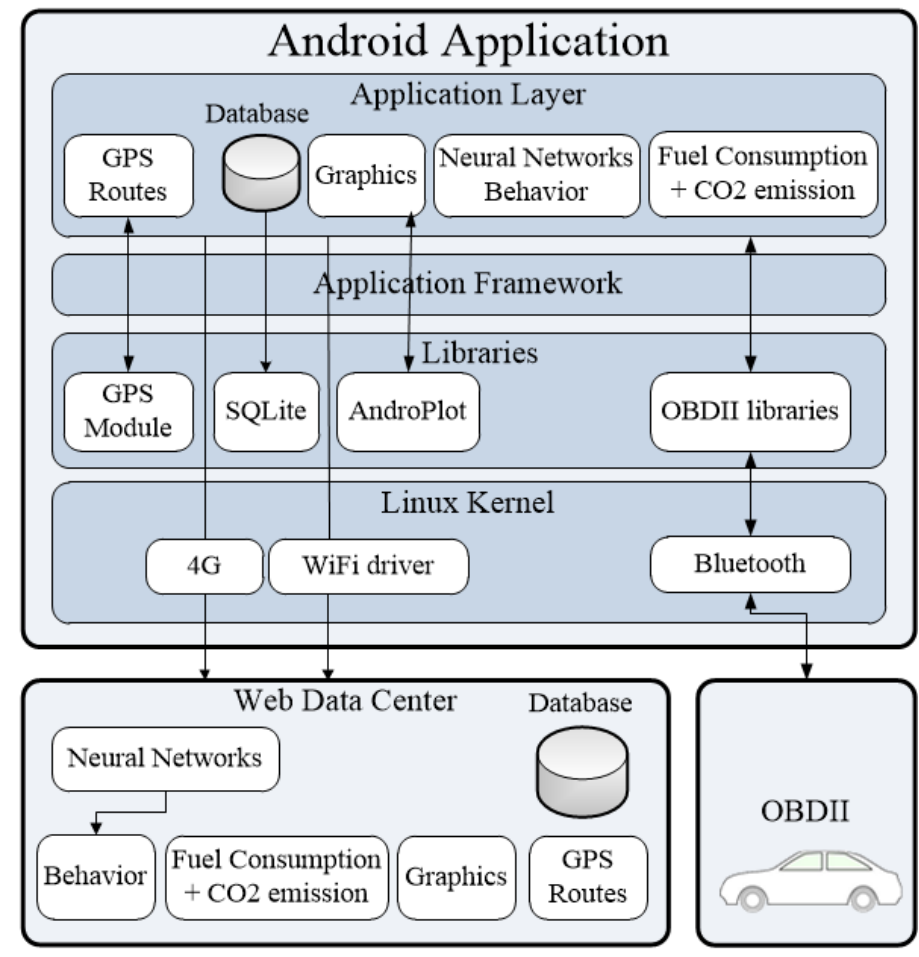

(b) Block diagram of the architecture

Figure 1: System architecture of DrivingStyles.

vehicles), we are able to closely relate both results, detailing the fuel savings achieved by soft driving patterns compared to aggressive ones.

\section{Overview of the DrivingStyles ArChitecture}

The DrivingStyles architecture applies data mining techniques (process of discovering patterns in large data sets involving, methods of artificial intelligence, machine learning, statistics, and database systems) to generate a classification of the driving styles of users based on the analysis of their mobility traces. Such classification is generated taking into consideration the characteristics of each route, such as whether it is urban, suburban, or highway.

Figure 1 shows the system architecture which comprises four elements:

1) An application for Android based smartphones (see figure 1.b). (i) Using an OBD-II Bluetooth interface, the application collects control information such as speed, acceleration, engine revolutions per minute, throttle position, and vehicle's geographic position (obtained from GPS mobile). (ii) In addition, we also obtain via OBD-II the mass flow sensor (MAF), manifold absolute pressure (MAP), and the intake air temperature (AIT) used in the calculation of fuel consumption. (iii) After gathering the information, the user uploads the route data to the remote data center for analysis.
2) A data center with a web interface to collect large data sets sent by different users concurrently, and to graphically display a summary of the most relevant results including the fuel efficiency. Our solution is based on open source software tools such as Apache, PHP and Joomla.

3) A neural network, which must be trained using the most representative route traces in order to correctly identify, for each path segment, the driver's style, as well as the segment profile: urban, suburban or highway. We use the backpropagation algorithm [15], which has proven to provide good results in classification problems such as the one associated to this project.

4) Integration of the tuned neural networks in the data center platform. The goal is to use neural networks to dynamically and automatically analyze user data, allowing users to find out their profiles as a driver, as well as their fuel consumption (which is related to their driving behavior), thus promoting a less aggressive and more ecological driving (see figure 2).

\section{A. Android Application and Web Interface}

The Android application is a key element of our system, proving connectivity to the vehicle and to the DrivingStyles web platform. Currently, it can be downloaded for free from the DrivingStyles website http://www.drivingstyles.info, or from Google Play https://play.google.com/store/apps/details? 
RNA DrivingStyles Route Type

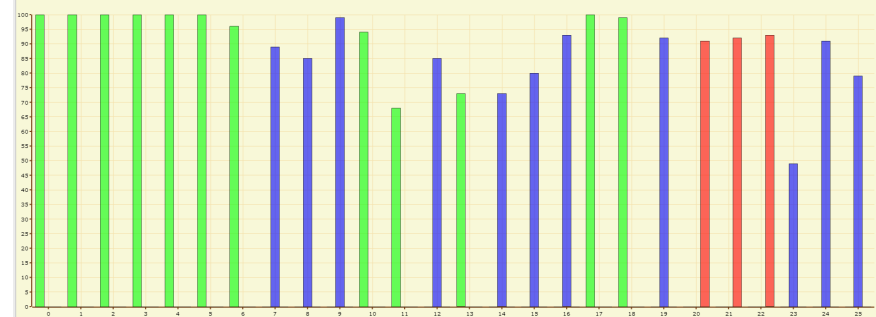

(a) Route type.
RNA DrivingStyles Route Behavior - - \% Quiet - \% Normal - \% Aggressive

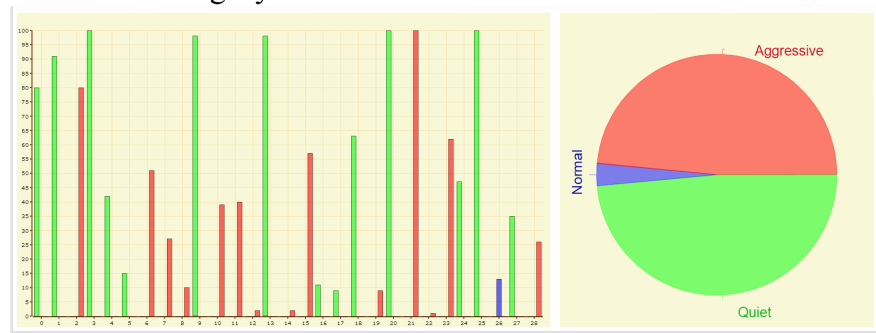

(b) Route behavior.

Figure 2: Snapshots of route type and behavior.

$i d=$ com.driving.styles (more than 4500 downloads).

The available functionalities are: (i) User creation, (ii) Connection options, (iii) GPS Activation, (iv) Sensor sampling.

Our application captures data sent by the OBD-II and the GPS interfaces, as well as the phone's accelerometer (see figure 3).

Besides showing the sensors that we are monitoring, we can perform several parallel actions without affecting the data captured.

The route upload module is in charge of sending the users' traces to the website data center for further analysis. This module can be accessed either from the historic stored routes, or immediately after stopping the data capture. The information screen displays the header information of the selected route, such as: (i) date of the captured data, (ii) start time, (iii) finish time, (iv) maximum speed and (v) fuel consumption.

Our application includes a graphical interface for showing the routes on a map, as well as the collected statistics. Additionally, it also includes communication facilities for uploading the collected routes to the data center.
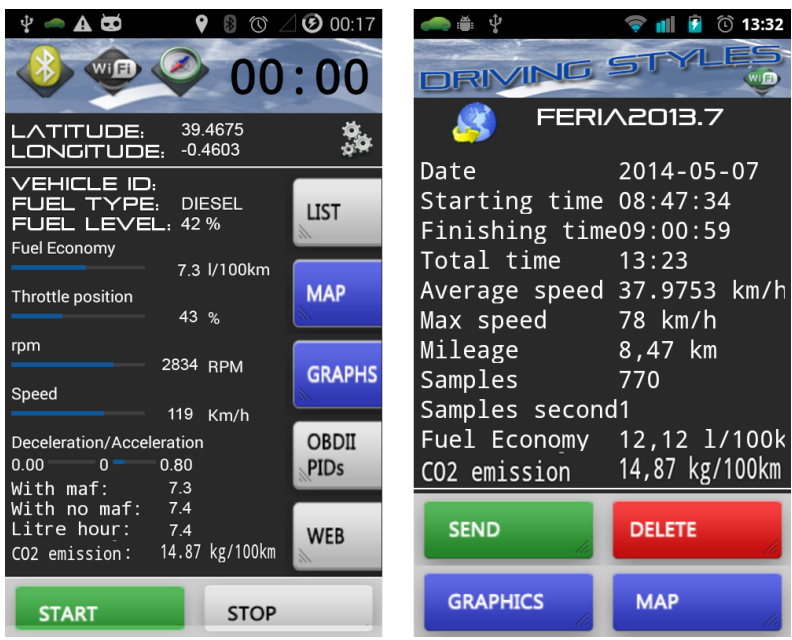

Figure 3: Snapshots of the main screen and the data sending module.

The second main component of our architecture corresponds to the data center and its web interface. For this, we have selected open source software such as Apache HTTP, and Joomla as the content management system (CMS). We have used a CMS, combined with the use of a resource wrapper, which detachs our system from the presentation layer, thus focusing on the problem of driving styles characterization and the influence of the latter fuel consumption. The URL of this module is http://www.drivingstyles.info.

Next, we present our fuel consumption estimation approach relating it with the driver style as captured by the DrivingStyles platform.

\section{Fuel Consumption / Instantaneous Fuel CONSUMPTION CALCULATION}

Fuel consumption is usually represented as the ratio of fuel consumed per distance travelled, being measured in terms of litres per 100 kilometres (or alternatively as MPG - miles per gallon). In this work we focus on petrol and diesel engines. Although the basic designs of gasoline and diesel engines are similar, the mechanics are different. A gasoline engine compresses its fuel and air charge, and then initiates combustion by the use of a spark plug. A diesel engine just compresses air until the combustion chamber reaches a temperature for self-ignition to occur. So, at a given speed in kilometres per hour, fuel consumption can be calculated as follows:

$$
\text { Fuel Consump. }[\mathrm{l} / 100 \mathrm{~km}]=\frac{\text { Fuel Flow }[\mathrm{l} / \mathrm{h}]}{\text { Speed }[\mathrm{km} / \mathrm{h}]} \cdot 100
$$

Instantaneous fuel economy/consumption is calculated from the current fuel flow and the current vehicle speed. It can be only be calculated when the vehicle is moving and the engine is operating.

$$
\text { Instanta. Fuel Consump. }[\mathrm{l} / \mathrm{km}]=\frac{\text { Fuel Flow }[\mathrm{l}]}{\text { Speed }[\mathrm{km}]}
$$

Again, not all vehicles support all the OBD PIDs, and there are usually many manufacturer-defined custom PIDs that are not defined in the OBD-II standard. So, the OBD standard does not provide a fuel consumption parameter; instead, it provides other values that enable its calculation. Depending on the 


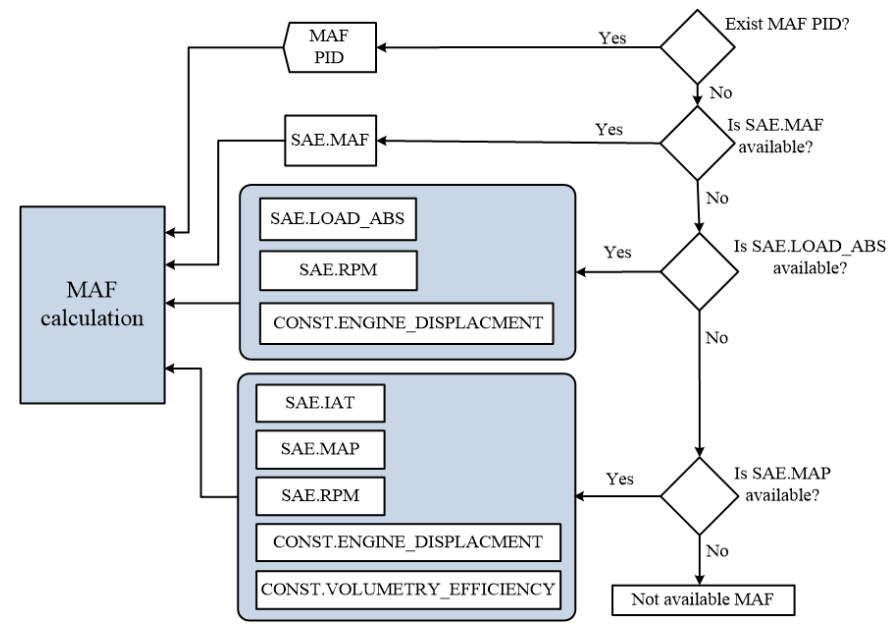

Figure 4: Scheme of the different possibilities of MAF calculation.

variables that the ECU can supply, the mathematical procedure to determine fuel consumption is different (see figure 4).

1) By combining the Engine Fuel Rate (PID 015E), also known as Fuel Flow (litres/hour), and Speed (PID 010D), it is easy to calculate fuel consumption. However, while speed is mandatorily available, fuel rate is not. In fact, it was unavailable in all the vehicles we used to carry out our tests. This can be due to two reasons: (i) the manufacturer chooses not to make it available, or (ii) there is no sensor inserted in the fuel line between the fuel tank and the engine carburetor to measure litres per hour.

2) If the MAF PID is available, but the Engine Fuel Rate is not, we can calculate fuel rate as Fuel Flow (litres/hour) by dividing the Mass Air Flow (PID 0110) · $3600 \mathrm{sec}$. by the product of air-to-fuel ratio and Fuel Density (see table I):

$$
\text { Fuel Flow }[l / h]=(M A F \cdot 3600) / A F R_{A} \cdot F D
$$

where $M A F$ refers to Mass Air Flow (g/s), $A F R_{A}$ to the actual Air-to-Fuel Ratio (see table I), and $F D$ - Fuel Density ( $\mathrm{g} / \mathrm{l}$, see table I), allowing us to directly calculate fuel consumption.

3) If MAF is not available there are two ways to calculate it (see figure 4).

- As a function of absolute load (PID 0143), RPM (PID 010C) and Engine Displacement (EngDisp, volume of an engine's cylinders in $\mathrm{cm}^{3}$, intake stroke is the fluid admission phase of a reciprocating cylinder). The equation is:

$$
\begin{aligned}
& \text { MAF }[\mathrm{g} / \mathrm{s}]= 1.184[\mathrm{~g} / \mathrm{l}] \cdot \text { EngDisp }[\mathrm{l} / \text { intakestroke }] \\
& \cdot \text { load abs } / 100 \cdot \text { enginespeed }[\mathrm{rpm}] \quad(4) \\
& / 2 \cdot[\mathrm{rpm} / \text { intakestroke }] / 60[\mathrm{sec} / \mathrm{min}]
\end{aligned}
$$

- As a function of the intake manifold pressure (PID 010B), RPM (PID 010C), intake air temperature (PID 010F) and

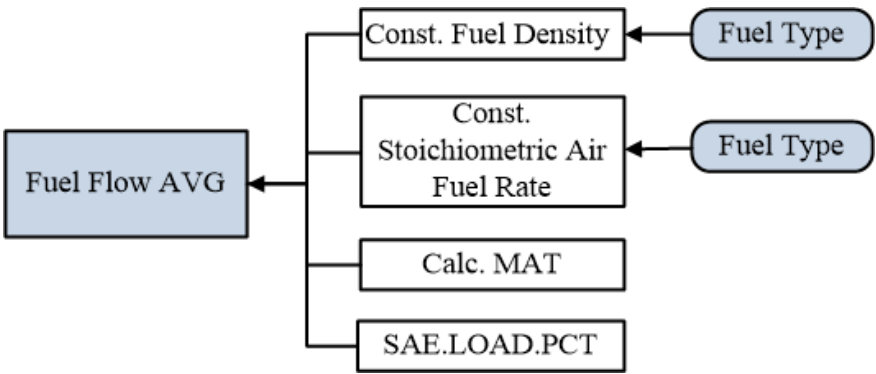

Figure 5: Outline of the calculation of the Fuel Flow average.

engine displacement. A synthetic variable called IMAP can be used to estimate the Mass Air Flow (MAF) of an internal combustion vehicle, much like a MAF sensor. In order to make this calculation, the engine displacement and volumetric efficiency of the engine must be provided.

$$
I M A P=R P M \cdot M A P / I A T / 2
$$

Where RPM (PID 010C) is the engine speed in RPM, MAP (PID 010B) is the Manifold Absolute Pressure measured in kilopascal $\mathrm{kPa}$, and IAT (PID 010F) is the Intake Air Temperature measured in degrees Kelvin. This integrated value can be converted into total air flow (grams) using the following formula:

$$
\begin{aligned}
M A F[g / s]= & (I M A P / 60) \cdot(\operatorname{VolEff} / 100) \\
& \cdot \text { EngDisp } \cdot M M A i r / R
\end{aligned}
$$

Where VolEff is Volume Efficiency (which relates the actual and the theoretical volumetric flow rate in \%), EngDisp is the Engine Displacement (the volume of an engine's cylinders in $\mathrm{cm}^{3}$ ) and $\mathrm{R}$ is $8.314 \mathrm{~J} /{ }^{\circ} \mathrm{K} /$ mole. These parameters are used to formulate the equation in order to obtain reliable OBD data, which is then compared to the data given by the vehicle manufacturer to ensure its accuracy.

The Air Fuel Flow can then be calculated as follows: (see figure 5).

$$
\text { Fuel Flow }[l / h]=(M A F \cdot 3600) / A F R_{A} \cdot F D
$$

\begin{tabular}{|c|c|c|}
\hline Fuel Type & Ratio by mass & Density $\mathrm{g} / \mathrm{dm}^{3}$ \\
\hline \hline Gasoline & $14.7: 1$ & 820 \\
\hline Diesel & $14.5: 1$ & 750 \\
\hline
\end{tabular}

Table I: Ideal air/fuel ratio (grams of air to 1 gram of fuel) Density $\left(\mathrm{g} / \mathrm{dm}^{3}\right)$.

\section{Greenhouse Gas Emissions Calculation}

The most significant greenhouse gases are generated from direct combustion carbon dioxide $\mathrm{CO}_{2}$, Methane $\left(\mathrm{CH}_{4}\right)$, and Nitrous oxide $\left(\mathrm{N}_{2} \mathrm{O}\right)$, among others. $\mathrm{CO}_{2}$ is always generated when burning fuel that contains carbon. Since the carbon in the fuel is combined with the oxygen in the air: $\mathrm{C}+\mathrm{O}_{2} \rightarrow \mathrm{CO}_{2}$, the amount of $\mathrm{CO}_{2}$ can be calculated by the atomic masses 


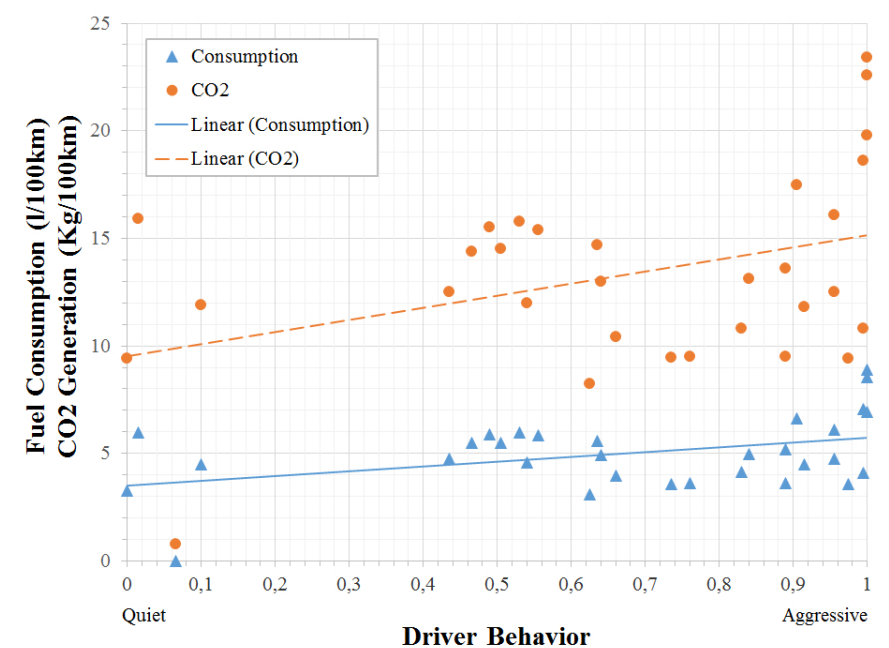

Figure 6: Chart of consumption and $\mathrm{CO}_{2}$ in relation to the driving behavior.

of carbon and oxygen and the carbon content of the fuel. The atomic mass of carbon is $12_{U}$ and oxygen is $16_{U}$, meaning that $C O_{2}=12_{U}+2 \cdot 16_{U}=44_{U}$. Burning $1 \mathrm{~kg}$ of carbon produces $44 / 12 \approx 3,67 \mathrm{~kg}$ of $\mathrm{CO}_{2}$ in complete combustion, and so the $\mathrm{CO}_{2}$ emission of combustion is $3,67 \cdot C_{c} \cdot m_{\text {fuel }}$ where $C_{c}=$ fuel carbon content (mass bassis). Considering that the carbon content of diesel fuel is $85,7 \%$ the $\mathrm{CO}_{2}$ emission when burning $1 \mathrm{~kg}\left(m_{\text {fuel }}=1 \mathrm{~kg}\right)$ of diesel fuel is:

$$
\begin{aligned}
m_{\mathrm{CO}_{2}}= & 3,67 \cdot C_{c} \cdot m_{\text {fuel }} \\
m_{\mathrm{CO}_{2}=}= & 3,67 \cdot 0,857 \cdot 1[\mathrm{~kg}]=3,15[\mathrm{~kg} / 1 \mathrm{~kg} \text { fuel }] \\
& \text { Density of diesel fuel is } 0,84[\mathrm{~kg} / \mathrm{l}] \\
m_{\mathrm{CO}_{2}}= & 3,15[\mathrm{~kg}] \cdot 0,84=2,64[\mathrm{~kg} / 1 \mathrm{l} \text { fuel }]
\end{aligned}
$$

Driving in a fuel-efficient manner can save fuel, money, and reduce greenhouse gas emissions. Among the factors that can affect fuel consumption, such as: vehicle age and condition, outside temperature, weather, and traffic conditions, we consider that driver behavior can be the most relevant parameter.

\section{EXPERIMENTAL RESUltS AND EVALUATION}

In our project, we focus on measuring fuel consumption variations associated with different driver behaviors. In order to achive this objetive, we rely on the collaboration of 264 drivers from around the world using our platform, including countries like India, Brazil, Central America, and Europe [16]. In this particular study, we analyzed the behavior of 34 representative routes (each divided into 20 second periods) using the neural network described earlier. For each section, the neural network returns the corresponding driver behavior, and we combine this data with the fuel consumption data corresponding to that route.

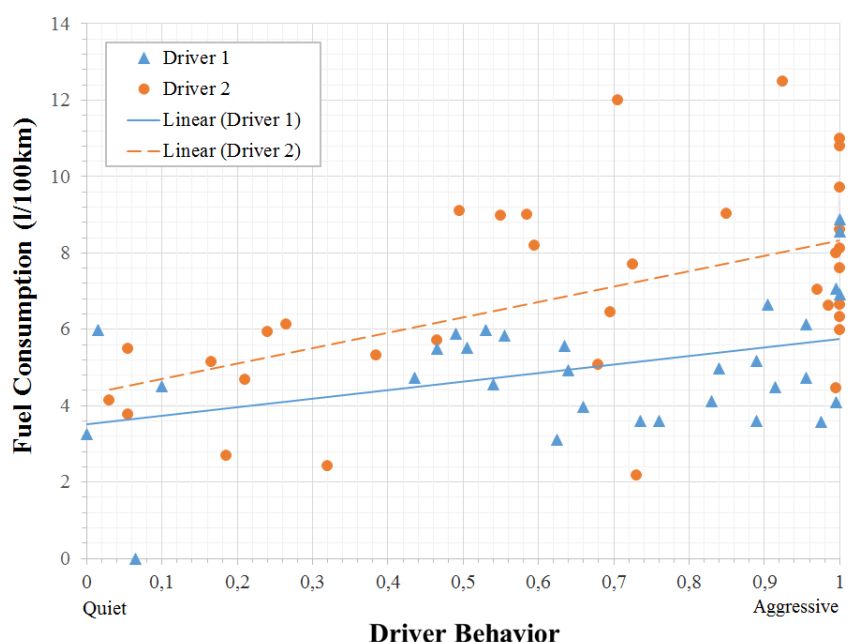

Figure 7: Comparative chart between two drivers and their behavior.

We carried out several types of tests to validate our proposals. The first requires a same person to drive a single vehicle model, and then analyzing all the behaviors recorded during driving, as well as the instantaneous consumption. The results of this test have been very significant, as shown in figure 6. Notice that more aggressive driving behaviors cause consumption to increase significantly, liters of fuel, likewise increasing the generation of $\mathrm{CO}_{2}$.

Figure 8 displays the differences between quiet, normal, and aggressive driving behavior in terms of fuel consumption; aggressive drivers provoke fast starts and quick accelerations, driving at high engine revolutions, and causing sudden speed changes. Conversely, a quiet driving behavior would be smooth, without sudden speed changes or continuos gear shifts. It is clear that fuel consumption increases when the driver behavior becomes more aggressive, with average differences of up to 1,5 liters per $100 \mathrm{~km}$. Regarding $\mathrm{CO}_{2}$ emissions, they increase by $50 \%$, going from 10 to $15 \mathrm{Kg} / 100 \mathrm{~km}$, dependending on whether you are a quiet or an aggressive driver, as shown in figure 6.

The second battery of tests was performed using the same vehicle but with different drivers. Figure 7 shows the behavior of two drivers driving the same vehicle. We can see that the behavior of both drivers is clearly different, being that the second driver clearly has a more aggressive behavior, and so consumption is noticeably higher compared to the other driver.

As a result, we conclude that aggressive driving behaviors, besides being dangerous and not recommended, can be economically expensive and ecologically harmful. A trend towards aggressive driving behavior may actually increase fuel costs by more than $20 \%$, not to mention that additional $\mathrm{CO}_{2}$ emissions to the environment could be avoided. 


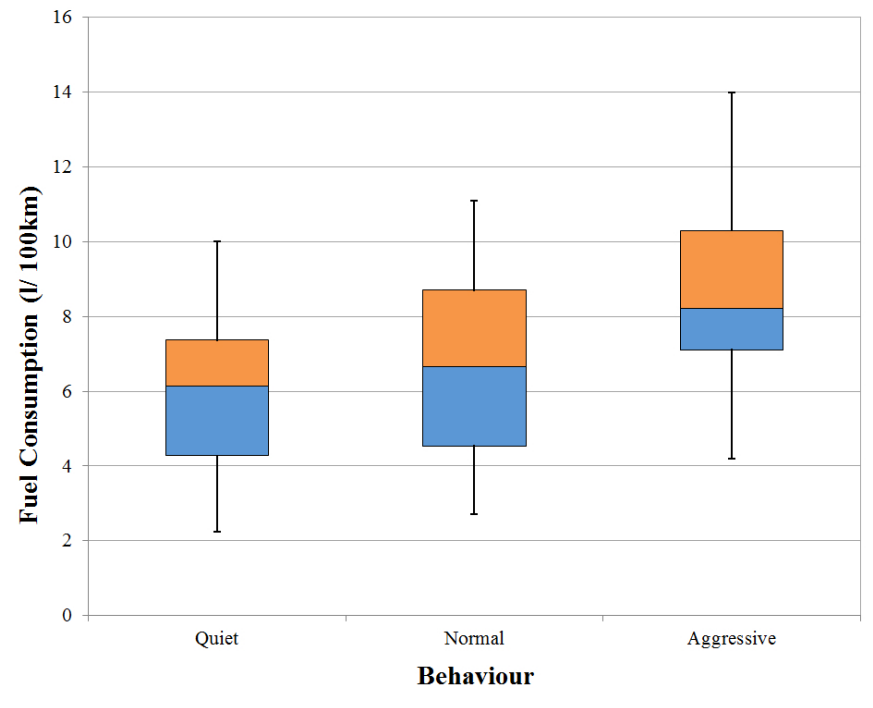

Figure 8: Box and wisker plot of Fuel Consumption / Driving Behavior.

\section{CONCLUSIONS AND FUTURE WORK}

Reducing energy consumption and greenhouse gas emissions requires drivers to adopt an efficient driving style. This paper presents our DrivingStyles platform, which integrates mobile devices with data obtained from the Electronic Control Unit (ECU) to determine the type of road where the driver is traveling, as well as his driving habits. Using only an Android Smartphone and an OBD-II adapter, it is possible for a driver to improve his driving behavior and fuel efficiency, motivating him to improve his driving behavior.

In this paper, it has been demonstrated that the driving style is directly related to fuel consumption. Specifically, adopting an efficient driving style allows achieving fuel savings ranging from 15 to $20 \%$. An aggressive driving style always results in a greater energy consumption and $\mathrm{CO}_{2}$ emissions, whereas smooth driving ends up providing a greater energy efficiency as well as reduced gas emissions.

The application, which is available for free download in the DrivingStyle's website and in the Google Play Store, has achieved more than 4500 downloads from different countries in just a few months.
As future work, we intend to extend this platform to provide driving recommendations based on real-time feedback about the driver's health conditions and the instant driving pattern.

\section{ACKNOWLEDGMENTS}

This work was partially supported by the Ministerio de Ciencia e Innovación, Spain, under Grant TIN2011-27543C03-01.

\section{REFERENCES}

[1] International Organization for Standardization, 1999: Road vehicles, Diagnostic systems, Keyword Protocol 2000, 1999.

[2] ELM327DS. OBD to RS232 Interpreter. Elm Electronics Circuits for the Hobbyist.

[3] Meseguer,J.E., Calafate, C.T., Cano, J.C., Manzoni, P “DrivingStyles: a smartphone application to assess driver behavior" 18th IEEE symposium on Computers and Communications (ISCC 2013)

[4] Co Eco-Driving: Pilot Evaluation of Driving Behavior Changes among U.S. Drivers.

[5] E.Erikcsson. Independent driving pattern factors and their influence on fuel-use and exhaust emission factors Transportation Research Part D: Transport, 2001 Elsevier, 325-345J.

[6] Johansson, H., Gustafsson, P., Henke, M., Rosengren, M., 2003. Impact of EcoDriving on emissions. International Scientific Symposium on Transport and Air Pollution, Avignon, France.

[7] D.Y.C. Leung, D.J. Williams, Modelling of Motor Vehicle Fuel Consumption and Emissions Using a Power-Based Model, Environmental Monitoring and Assessment, 65:21-29,2000

[8] COPERT III, Computer programme to calculate emissions from road transport Methodology and emission factors (Version 2.1), Technical report No 49

[9] HORIBA, On Board PM Mass Measurement for US and EU In Use Compliance, Cambridge Particle Meeting 16th May 2008

[10] Kuhler, M., Kartens, D., Improved driving cycle for testing automotive exhaust emissions. SAE Technical Paper Series 780650. 1978

[11] André, M., 1996. Driving cycles develop-ment: Characterization of the methods. SAE Technical Papers Series 961112

[12] Fomunung, I., Washington, S., Guensler, R. A statistical model for estimating oxides emissions from light duty motor vehicles. Transportation Research Part D, pp.333-352. 1999

[13] BMW Press Release: Drive a BMW and enjoy personalised radio. [available at http://www.zercustoms.com/news/BMW-Connected-DrivePersonalised-Radio.html]

[14] V Barabba, C Huber, F Cooke, N Pudar, J Smith A multimethod approach for creating new business models: The General Motors OnStar project

[15] Hecht-Nielsen, R., Theory of the backpropagation neural network Neural Networks, 1989. IJCNN., International Joint Conference.

[16] http://drivingstyles.info/index.php/en/users-world

[17] IDEA (Institute for Energy Diversification and Saving of Energy). Manual of eco-driving for cars. January 2007.

[18] Traffic: civilization or barbarism. The risk Observatory. Institute for security studies (IDES). URL: http://www.seguretat.org. 2006. 